\title{
A phase III trial comparing CHOP to PMitCEBO with or without G-CSF in patients aged 60 plus with aggressive non-Hodgkin's lymphoma
}

\section{Burton', D Linch', P Hoskin², D Milligan ${ }^{3}$, MJS Dyer ${ }^{4}$, B Hancock ${ }^{5}$, P Mouncey', P Smith', W Qian', $K_{\text {MacLennan }}{ }^{7}$, A Jack ${ }^{7}$, A Webb ${ }^{8}$ and D Cunningham ${ }^{*, 8}$}

'University College London and CRUK Clinical Trials Centre, 222 Euston Road, London NWI 2DA, UK; ${ }^{2}$ Mount Vernon Hospital, Rickmansworth Road, Northwood HA6 2RN, UK; ${ }^{3}$ Birmingham Heartlands Hospital, Bordesley Green East, Birmingham B9 5SS, UK; ${ }^{4}$ University of Leicester, Lancaster Road, Leicester LEI 9HN, UK; ${ }^{5}$ Weston Park Hospital, Whitham Road, Sheffield SI 0 2SJ, UK; ${ }^{6}$ MRC Clinical Trials Centre, 222 Euston Road, London NWI 2DA, UK: ${ }^{7}$ Leeds General Infirmary, Great George Street, Leeds LSI 3EX, UK; ${ }^{8}$ Department of Oncology, Royal Marsden Hospital, Downs Road, Sutton, Surrey SM2 5PT, UK

The management of older patients with aggressive non-Hodgkin's lymphoma presents a challenge to the physician. Age is a poor prognostic indicator, due to reduced ability to tolerate and maintain dose-intensive chemotherapy. Generally, older patients demonstrate a lower response rate, reduced survival and increased toxicity, although the majority of large randomised trials exclude older patients. This randomised trial was conducted in patients 60 years or over to compare CHOP (cyclophosphamide $750 \mathrm{mg} \mathrm{m}^{-2}$, doxorubicin $50 \mathrm{mg} \mathrm{m}^{-2}$, vincristine $1.4 \mathrm{mg} \mathrm{m}^{-2}$, prednisolone $100 \mathrm{mg}$ ) with PMitCEBO (mitoxantrone $7 \mathrm{mg} \mathrm{m}^{-2}$, cyclophosphamide $300 \mathrm{mg} \mathrm{m}^{-2}$, etoposide $150 \mathrm{mg} \mathrm{m}^{-2}$, vincristine $1.4 \mathrm{mg} \mathrm{m}^{-2}$, bleomycin $10 \mathrm{mg} \mathrm{m}^{-2}$ and prednisolone $50 \mathrm{mg}$ ). Due to the myelosuppressive nature of these regimens, patients were also randomised to the addition of G-CSF. The formal results of this trial with long-term follow-up are now reported. Data were analysed to assess efficacy and toxicity. Overall response rate was $84 \%$ in the CHOP arm and $83 \%$ in the PMitCEBO arm, with overall response rates of $83 \%$ for the use of G-CSF and $84 \%$ for no G-CSF. At median 44 months follow-up, there was no significant difference in failure-free, progression-free or overall survival between the $\mathrm{CHOP}$ and PMitCEBO arms. At 3 years, the actuarial failure-free survival was $44 \%$ in $\mathrm{CHOP}$ recipients and $42 \%$ in $\mathrm{PMitCEBO}$ recipients and the 3 -year actuarial overall survival was $46 \%$ and $45 \%$ respectively. There was no significant difference in the failurefree, progression-free or overall survival with the addition of G-CSF.

British Journal of Cancer (2006) 94, 806-8I3. doi: I0.1038/sj.bjc.6602975 www.bjcancer.com

Published online 28 February 2006

(c) 2006 Cancer Research UK

Keywords: elderly; non-Hodgkin's lymphoma; CHOP; PMitCEBO; G-CSF

The reported incidence of aggressive non-Hodgkin's lymphomas (NHL) has doubled in recent decades, and this increase has been predominantly observed in older patients (McNally et al, 1999; 2001 Census; Muller et al, 2005). Advanced age is an independent poor prognostic factor, with inability to tolerate chemotherapy and maintain dose intensity (International NHL Prognostic Factors Project, 1993; NHL Classification Project, 1997; Bastion et al, 1997). Higher treatment-related mortality has also been reported in older patients using the CHOP (cyclophosphamide, doxorubicin, vincristine and prednisolone) regimen (Armitage and Potter, 1984). For these reasons, specific regimens have been developed for treating elderly patients, involving dosage reductions and shortening of the period of treatment (Meyer et al, 1995; Sonneveld et al, 1995). These curtailed regimens have tended to result in a

*Correspondence: Professor D Cunningham;

E-mail: david.cunningham@icr.ac.uk

Received 22 November 2005; revised 3 January 2006; accepted 5 January 2006; published online 28 February 2006 lower toxic death rate but also a lower complete response (CR) rate.

The British National Lymphoma Investigation (BNLI) group have had considerable experience with the 12 weekly PACEBOM regimen (prednisolone, adriamycin, cyclophosphamide, etoposide, bleomycin, vincristine, methotrexate), which alternates myelosuppressive and non-myelosuppressive agents (Sweetenham et al, 1991). In a randomised trial in patients under the age of 70 years, PACEBOM was shown to be as efficacious as CHOP (Linch et al, $2000)$. One potential advantage of the PACEBOM regimen is the lower planned total dose of anthracycline (30\% reduction), which might be particularly relevant to the older patient. Several recent studies have shown that anthracycline-related cardiotoxicity is more frequent in older patients (Limat et al, 2003; Swain et al, 2003). Swain et al suggested that the threshold for cardiac damage is doxorubicin $400 \mathrm{mg} \mathrm{m}^{-2}$. Limat et al suggested it is even lower. The tolerability of PACEBOM in the older population though was frequently limited by mucositis, and subsequently the methotrexate was omitted. This PACEBO regimen was then compared in a randomised trial, in elderly patients with histologically aggressive 
NHL, with PMitCEBO, in which the $35 \mathrm{mg} \mathrm{m}^{-2}$ adriamycin was replaced by $7 \mathrm{mg} \mathrm{m}^{-2}$ mitoxantrone, an anthracenedione derivative (Mainwaring et al, 2001). This trial suggested that PMitCEBO was superior to PACEBO, with an encouraging $40 \%$ survival at 4 years. This contrasts with the findings in another trial where the substitution of adriamycin by mitoxantrone had a negative impact (Sonneveld et al, 1995). In the trial reported here, PMitCEBO has been compared with standard CHOP.

Both the PMitCEBO and CHOP regimens result in considerable myelosuppression in the elderly population and the value of using granulocyte colony-stimulating factor (G-CSF) to mitigate against the chemotherapy induced neutropenia was also explored. Previous studies in lymphoma have suggested that the use of GCSF results in less granulocyte suppression, less infection and hospitalisation, possibly allowing a higher dose intensity with improved response rates and with significant economic benefits (Pettengell et al, 1992; Gerhartz et al, 1993; Bertini et al, 1994; Zagonel et al, 1994; Niitsu and Umeda, 1995; Silvestri et al, 1995). Few previous studies have been adequately powered, however, to evaluate the impact of G-CSF use on survival. In the trial reported here, the use of G-CSF in combination with chemotherapy has been compared with chemotherapy alone.

The mature results of this study of 784 patients are presented in this paper.

\section{PATIENTS AND METHODS}

\section{Patient selection}

Patients were eligible if aged 60 years or over with previously untreated, bulky stage IA or stages IB-IV aggressive NHL. There was no upper age limit. Between 1997 and 1999 patients with a histological diagnosis of diffuse mixed cell, diffuse large cell or diffuse immunoblastic lymphoma according to the Working Formulation were included. From 2000 the histological diagnosis was made according to the World Health Organisation and patients with diffuse large B-cell lymphoma were included. Central review including immunophenotyping was performed at a later date in 627 cases and in $52(8 \%)$ the patient was considered ineligible on histological criteria either because of a change in diagnosis or because of inadequate material. The analyses performed were on an intention to treat basis and patients were not excluded after randomisation.

Full clinical staging with routine haematological and biochemical blood tests, computed tomography (CT) imaging of the chest, abdomen and pelvis and bone marrow biopsy were performed. Any patient with central nervous system disease, lymphoblastic or Burkitt lymphoma was excluded from the trial. Patients with significant renal, hepatic or cardiac dysfunction were excluded (creatinine $>150 \mu \mathrm{moll}^{-1}$, bilirubin $>35 \mu \mathrm{moll}^{-1}$, left ventricular ejection fraction $<50 \%$, respectively). No patients with medical conditions, other than aggressive non-Hodgkin's lymphoma, prohibiting intensive therapy were included and no patient had received systemic treatment for cancer in the preceding 5 years.

\section{Trial design}

Between October 1997 and September 2003, 784 newly diagnosed patients from 92 centres in UK were entered into the trial. The trial had a $2 \times 2$ factorial design; randomisations between CHOP and PMitCEBO (comparing all patients randomised to CHOP with all patients randomised to PMitCEBO) and the addition or not of GCSF (comparing all patients randomised to G-CSF with all those patients not randomised to G-CSF).

The CHOP regimen was given 3-weekly for a maximum of eight cycles and the PMitCEBO regimen weekly for a maximum of 16 weeks (Table 1). Prophylactic G-CSF (Lenograstim) $263 \mu \mathrm{g} \mathrm{day}^{-1}$ was administered if randomised to G-CSF from days 8 to 14 in the CHOP arm and days 6 to 12 in the PMitCEBO arm. All patients received allopurinol for weeks $1-3$ and co-trimoxazole prophylaxis week 1 to treatment end plus 2 weeks. Patients treated with CHOP chemotherapy were assessed clinically and by CT imaging after 2, 4 and 6 cycles. If CR or non-progressive partial remission (PR) was achieved, patients were treated with six cycles of CHOP. If in a progressive PR at six cycles, two further cycles of CHOP were given. For patients treated with PMitCEBO, initial response was assessed clinically and by CT imaging after 4, 8 and, if applicable, 12 weeks. Patients were treated to CR or nonprogressive PR, plus a further 4 weeks of chemotherapy. Methotrexate $12.5 \mathrm{mg}$ intrathecally was given as six doses at weekly intervals to patients with peripheral blood, orbital, testicular or facial sinus disease.

Dose reduction was identical for both chemotherapy regimens and based on Southwest Oncology Group studies (Fisher et al, 1993). No dose modifications were made on the first cycle based on blood counts. Dose modifications for haematological toxicity for subsequent cycles were made as presented in Table 2. No dosage reduction was made for low haemoglobin. Blood transfusions were given to maintain haemoglobin $>10 \mathrm{~g} \mathrm{dl}^{-1}$. The dose of anthracycline was also reduced by 50 or $75 \%$ if the serum bilirubin was raised to 35-50 or $>50 \mu \mathrm{moll}^{-1}$, respectively. Bleomycin was discontinued if there were any clinical signs or radiological evidence of pulmonary infiltration/fibrosis developing. Bleomycin was also discontinued if severe skin toxicity developed. Vincristine was reduced by $50 \%$ in patients with grade 2 motor toxicity (mild, objective weakness, but no significant impairment of function) and

Table I Treatment regimens for $\mathrm{CHOP}$ and PMitCEBO

\begin{tabular}{|c|c|}
\hline CHOP & PMitCEBO \\
\hline 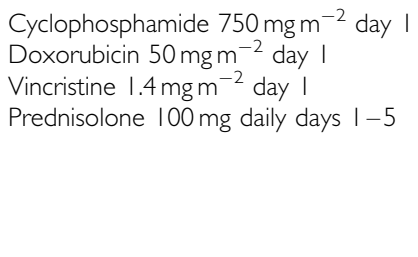 & $\begin{array}{l}\text { Cyclophosphamide } 300 \mathrm{mg} \mathrm{m}^{-2} \text { day I } \\
\text { Mitoxantrone } 7 \mathrm{mg} \mathrm{m}^{-2} \text { day I } \\
\text { Etoposide } 150 \mathrm{mg} \mathrm{m}^{-2} \text { day I } \\
\text { Prednisolone } 50 \mathrm{mg} \text { daily weeks I-4, } 50 \mathrm{mg} \text { alternate days week } 5 \text { to } \\
\text { treatment end } \\
\text { Vincristine } 1.4 \mathrm{mg} \mathrm{m}^{-2} \text { day } 8 \\
\text { Bleomycin } 10 \mathrm{mg} \mathrm{m}^{-2} \text { day } 8\end{array}$ \\
\hline
\end{tabular}

Table 2 Dose modifications due to haematological toxicity, cycle 2 onwards

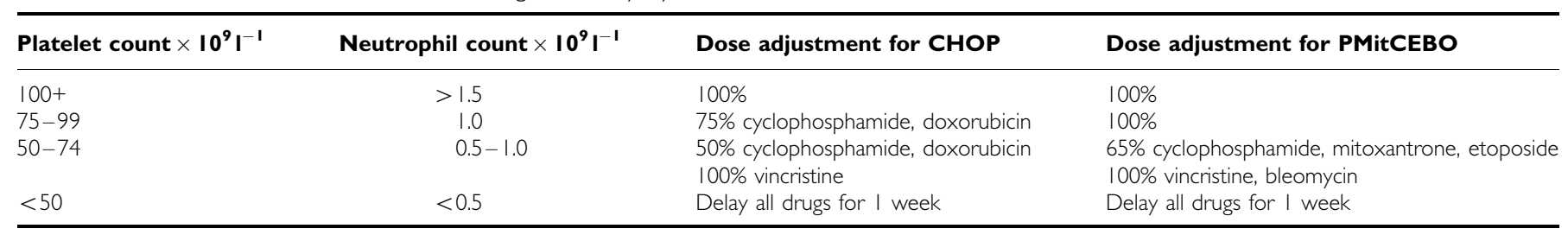


grade 3 sensory toxicity (severe objective sensory loss or paraesthesiae interfering with function). Vincristine was completely omitted for higher grades of toxicity.

\section{Response assessment}

Computed tomography imaging was used to assess response as in Table 3. This was repeated 1 and 3 months after completion of chemotherapy. Further clinical assessment continued 3-monthly for the first year, 6-monthly for 5 years and annually thereafter. Symptoms relating to cardiac status were elicited on each occasion.

\section{Statistical considerations}

This trial had a $2 \times 2$ factorial design and the primary end point for both randomisations was failure-free survival (FFS) defined as the time from the date of randomisation to the date of progression or death from disease, including non-responders, or death from treatment toxicity. Secondary end points for the comparison of CHOP with PMitCEBO and for the addition of G-CSF were response rates, toxicity, progression-free survival (PFS) and overall survival (OS). Progression-free survival was calculated from the date of randomisation to the date of progression or death from any cause whichever occurred first. Duration of OS was calculated from the date of randomisation to the date of death from any cause. At the time of the analysis, survivors were censored at the date they were last known to be alive. The log-rank test was applied to compare the Kaplan-Meier curves for FFS, PFS and OS (Kaplan and Meier, 1958). The standard $\chi^{2}$ test for frequency was used to compare response rate (CR) of treatment. Additional secondary end points for the G-CSF intervention were the number of inpatient days with and without sepsis.

The trial was powered to detect a $10 \%$ difference in the primary end point of FFS (assuming that the 3 year FFS with CHOP alone would be $30 \%$ ), with a power of $90 \%$ and a significance level of $5 \%$ in a two-sided log-rank test for each of the two variables. Thus, the calculated sample size was 880 patients (440 in each arm). All analyses were on an intention to treat basis.

\section{RESULTS}

Over 6 years, 784 eligible patients were entered into the trial. It was then closed prematurely following guidance from the UK National Institute for Clinical Excellence (NICE) that Rituximab should be given in combination with chemotherapy in all patients with diffuse large B-cell lymphoma. The median age of patients entered was 70 years (range 60-89). There were 411 (52\%) male and 373 (48\%) female patients. The proportion of patients with age adjusted international prognostic index risk (IPI) scores of 0,1 , 2,3 was $16,30,37$ and $17 \%$, respectively. Over half the patients thus had poor prognostic disease.

Table 3 Criteria for response assessment

\begin{tabular}{ll}
\hline Response & Definition \\
\hline CR & $\begin{array}{l}\text { Resolution of all clinical and radiological abnormalities } \\
\text { detected at presentation } \\
\\
\end{array}$ \\
PR & of two diameters \\
& No further reduction in previously responding disease \\
Non-progressive PR & Further reduction in previously responding disease \\
Progressive PR & $<50 \%$ response subdivided into: (i) progressive disease \\
Nonresponse & if $>50 \%$ increase in disease volume or development of \\
& new lesions; (ii)stable disease if disease status \\
& insufficient to meet criteria of partial response or \\
& progressive disease
\end{tabular}

Of these eligible patients, 195 patients were randomised into the CHOP arm, 202 into the PMitCEBO arm, 192 into the CHOP + GCSF arm, and 195 into the PMitCEBO + G-CSF arm. The four cohorts were well balanced for all clinical characteristics (Table 4). Histological subtypes were well matched between the four cohorts. $\mathrm{T}$-cell immunophenotype was seen in eleven cases in the CHOP arm, six cases in the PMitCEBO arm, seven cases in the CHOP + G$\mathrm{CSF}$ arm and nine cases in the PMitCEBO + G-CSF arm. Analysis of the primary end point of FFS, revealed no significant interaction between the two randomisations $(P=0.22)$ and the trial has therefore been analysed in accordance with the $2 \times 2$ factorial design, comparing the two CHOP cohorts with the two PMitCEBO cohorts and the two regimens with and without G-CSF. Data on the individual four treatment arms are only shown for reasons of exploratory or clinical information.

Of the CHOP recipients, $25 \%$ of patients received less than six cycles of chemotherapy predominantly due to early treatment failure. In total, $59 \%$ of patients received six cycles and $16 \%$ received more than this. In the PMitCEBO arm, $15 \%$ received less than eight cycles, $65 \%$ received 8-12 cycles, and $19 \%$ received $13-16$ cycles. Of the patients randomised to receive G-CSF, it was given in $99 \%$ and of those randomised not to receive G-CSF, it was given in $8 \% ; 17$ patients in the CHOP arm and 12 patients in the PMitCEBO arm. In the majority of cases, G-CSF was given to maintain dose intensity due to haematological toxicity (fourteen patients) or as secondary prophylaxis (four patients). This was mainly initiated between courses 2 and 4 . In the remaining cases, G-CSF was given due to a transcription error or the reason was not known. The use of radiation therapy was not stipulated in the protocol. Generally, involved field radiotherapy was given at the

Table 4 Patient characteristics

\begin{tabular}{|c|c|c|c|c|c|}
\hline & CHOP & PMitCEBO & $\begin{array}{c}\text { CHOP+ } \\
\text { GCSF }\end{array}$ & $\begin{array}{l}\text { PMitCEBO+ } \\
\text { GCSF }\end{array}$ & Total \\
\hline \multicolumn{6}{|l|}{ Age (years) } \\
\hline Median & 70 & 70 & 71 & 71 & 70 \\
\hline Range & $60-86$ & $60-89$ & $60-87$ & $60-85$ & $60-89$ \\
\hline \multicolumn{6}{|l|}{ Sex (\%) } \\
\hline Female & 46 & 48 & 48 & 48 & 48 \\
\hline Male & 54 & 52 & 52 & 52 & 52 \\
\hline \multicolumn{6}{|l|}{ Stage (\%) } \\
\hline 1 & 9 & 8 & 11 & 10 & 10 \\
\hline$\|$ & 29 & 30 & 24 & 23 & 27 \\
\hline III & 29 & 25 & 29 & 34 & 29 \\
\hline IV & 32 & 36 & 35 & 33 & 34 \\
\hline \multicolumn{6}{|c|}{ B Symptoms (\%) } \\
\hline A & 49 & 43 & 50 & 42 & 46 \\
\hline B & 51 & 57 & 50 & 58 & 54 \\
\hline \multicolumn{6}{|l|}{ WHO PS (\%) } \\
\hline 0 & 32 & 31 & 34 & 30 & 32 \\
\hline 1 & 41 & 43 & 37 & 38 & 40 \\
\hline 2 & 17 & 18 & 20 & 26 & 20 \\
\hline 3 & 8 & 6 & 6 & 4 & 6 \\
\hline 4 & 2 & 2 & 2 & 3 & 2 \\
\hline \multicolumn{6}{|l|}{ LDH (\%) } \\
\hline Not raised & 39 & 43 & 34 & 36 & 38 \\
\hline Raised & 61 & 57 & 66 & 64 & 62 \\
\hline \multicolumn{6}{|l|}{ IPI (\%) } \\
\hline 0 & 18 & 20 & 16 & 11 & 16 \\
\hline 1 & 30 & 30 & 28 & 33 & 30 \\
\hline 2 & 39 & 34 & 37 & 37 & 37 \\
\hline 3 & 13 & 16 & 19 & 18 & 17 \\
\hline
\end{tabular}


end of treatment to sites of initial bulk or residual disease. This was administered to 40 patients $(10 \%)$ in the CHOP arm and 41 patients $(10 \%)$ in the PMitCEBO arm.

\section{Response rates}

The overall response rates for $\mathrm{CHOP}$ and $\mathrm{PMitCEBO}$ were almost identical at 84 and $83 \%$, respectively $(P=0.69)$, but the CR rate with $\mathrm{CHOP}$ (55\%) was significantly higher than with PMitCEBO (47\%, $P=0.035)$.
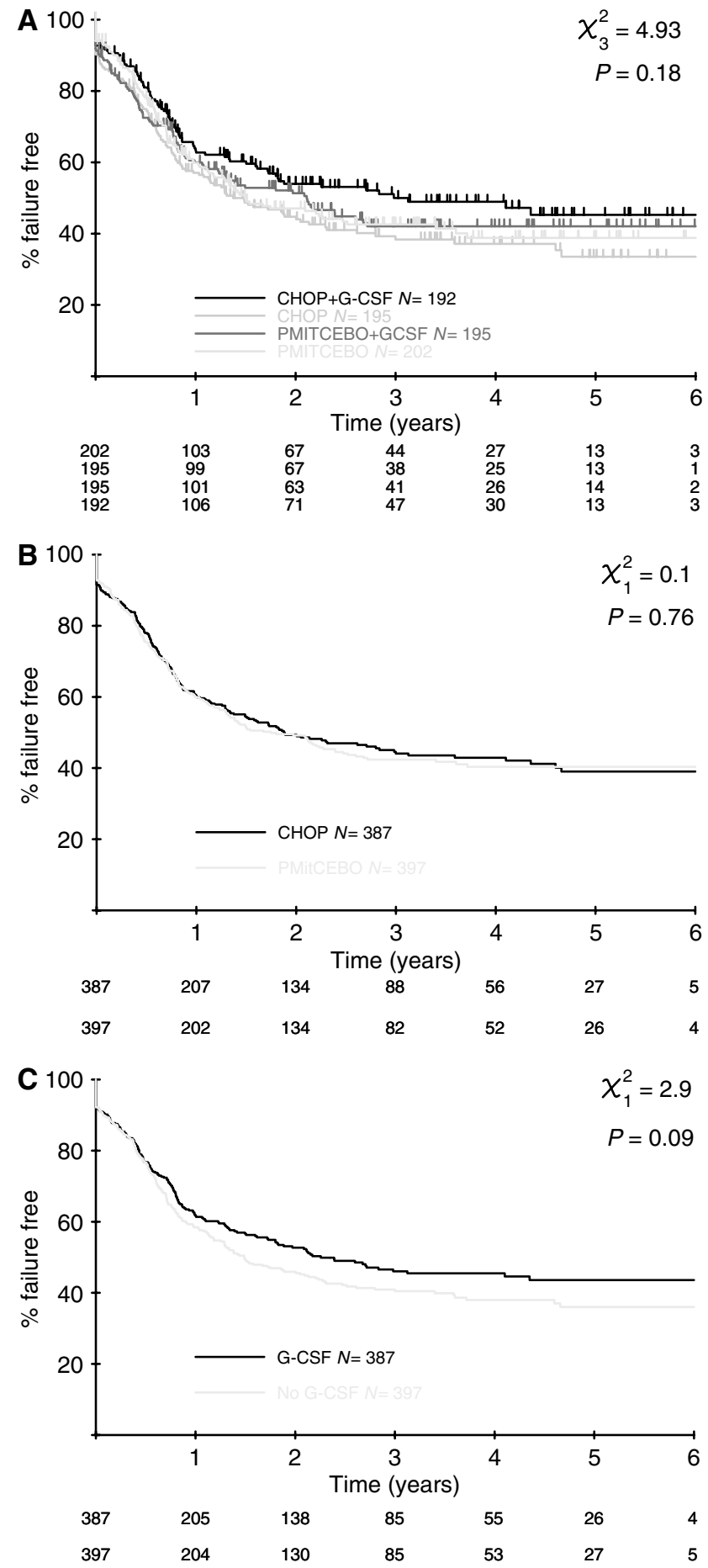

Figure I $(\mathbf{A}-\mathbf{C})$ Failure-free survival curves. (A) Failure-free survival all 4 arms; (B) failure-free survival CHOP vs PMitCEBO; (C) failure-free survival G-CSF vs no G-CSF.
The use of G-CSF had no impact on response rates with an overall response rate of $83 \%$ for the use of G-CSF and $84 \%$ for no G-CSF $(P=0.84)$. The CR rates of $52 \%$ with G-CSF and $50 \%$ without G-CSF were similar $(P=0.45)$.

\section{Survival}

At a median follow-up of 44 months, there was no significant difference in FFS between CHOP and PMitCEBO $(P=0.76)$. At 3 years, the actuarial FFS was $44 \%$ in CHOP recipients and $42 \%$ in PMitCEBO recipients (Figure 1B). There was also no significant difference in PFS $(P=0.77)$ or OS $(P=0.57)$ (Figure $2 \mathrm{~B})$. The
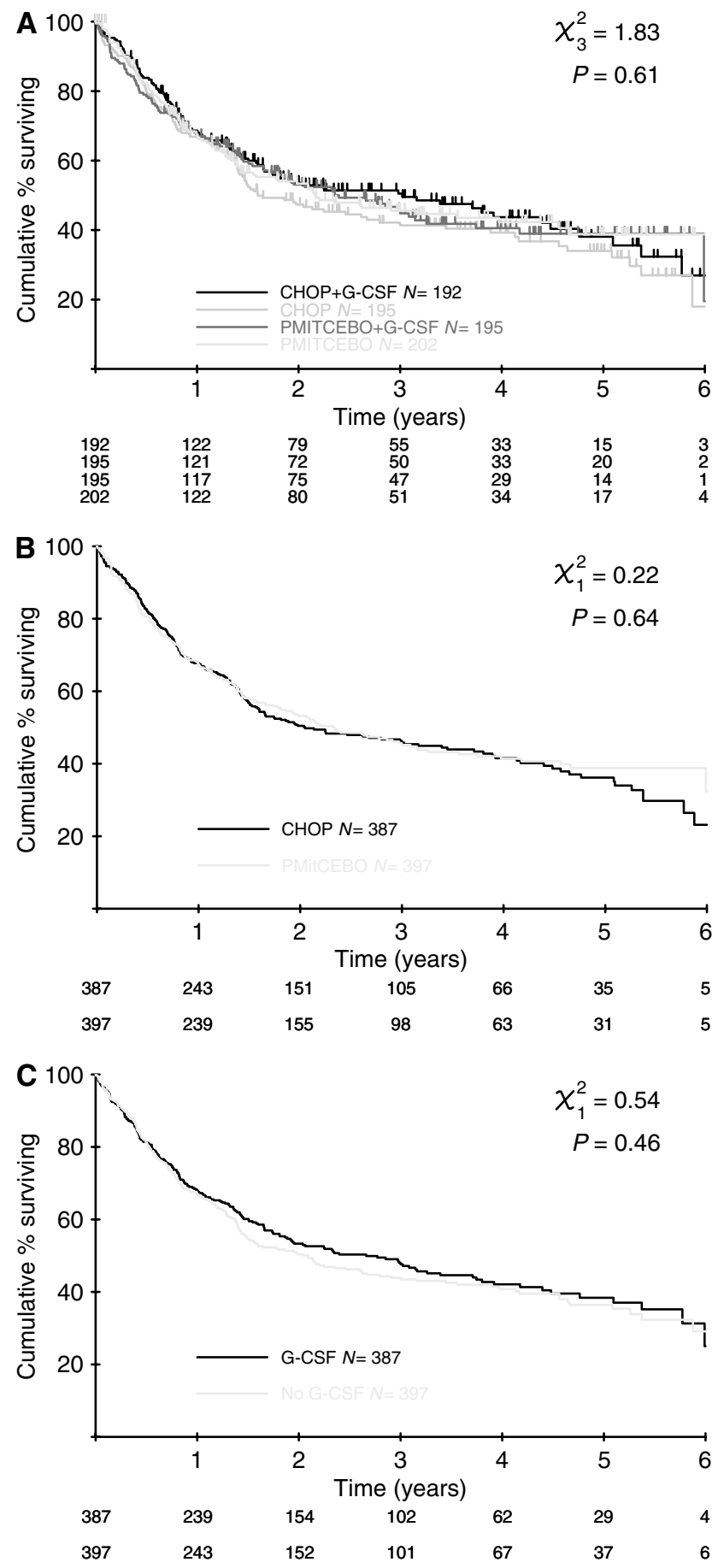

Figure 2 (A-C) Overall survival curves. (A) Overall survival all 4 arms; (B) overall survival CHOP vs PMitCEBO; $(\mathbf{C})$ overall survival G-CSF vs no G-CSF. 
Table 53 year failure-free and overall survival according to age and IPI score

\begin{tabular}{|c|c|c|c|c|}
\hline & CHOP & PMitCEBO & GCSF & No GCSF \\
\hline \multicolumn{5}{|c|}{3 year failure-free survival } \\
\hline Age (years) & $\%$ & $\%$ & $\%$ & $\%$ \\
\hline$<70$ & 48 & 47 & 50 & 45 \\
\hline$\geqslant 70$ & 40 & 38 & 42 & 36 \\
\hline \multicolumn{5}{|l|}{ IPI score } \\
\hline $0-1$ & 56 & 57 & 56 & 55 \\
\hline $2-3$ & 36 & 24 & 34 & 26 \\
\hline \multicolumn{5}{|c|}{ 3-year overall survival } \\
\hline Age years & $\%$ & $\%$ & $\%$ & $\%$ \\
\hline$<70$ & 53 & 52 & 54 & 51 \\
\hline$\geqslant 70$ & 39 & 38 & 41 & 36 \\
\hline \multicolumn{5}{|l|}{ IPI score } \\
\hline $0-1$ & 61 & 61 & 63 & 58 \\
\hline $2-3$ & 37 & 29 & 34 & 33 \\
\hline
\end{tabular}

3-year actuarial OS for patients receiving CHOP was $46 \%$ and for those receiving $\mathrm{PMitCEBO}$ was $45 \%$. In total, 419 patients in this trial $(53 \%)$ have died. In total, 318 were due to NHL, 158 in the $\mathrm{CHOP}$ arms and 160 in the PMitCEBO arms.

There was no significant difference in the FFS between those patients who received G-CSF and those who did not $(P=0.23)$ (Figure 1C). Similarly, there was no significant difference in PFS $(P=0.19)$ or $\mathrm{OS}(P=0.37)$ (Figure $2 \mathrm{C})$. Of the deaths due to NHL, there were 147 among patients randomised to receive G-CSF and 171 among those who were not.

Subgroup analysis was performed for all patients according to IPI scores and age. Patients with IPI score 0 and 1 were compared with patients with an IPI score of 2 and 3 and patients $<70$ years were compared with patients $\geqslant 70$ years. The analysis was performed for CHOP vs PMitCEBO and G-CSF vs no G-CSF. Patients $\geqslant 70$ years had a reduced FFS and OS compared to patients of $<70$ years, but there were no significant differences between any randomised arms for either age cohort (Table 5). The poor prognosis patients also had a significantly reduced 3-year FFS and OS but no difference was apparent between randomisations (Table 5).

\section{Toxicity}

The occurrence of grade 3 and 4 haematological toxicity was significantly more frequent in the PMitCEBO arm $(63 \%$ of patients) compared with the CHOP arm $(42 \%) \quad(P<0.0001)$ (Table 6). This was mainly due to the increased incidence of leucopenia in the PMitCEBO arm (60\%) compared to CHOP (39\%) $(P<0.0001)$ (Table 7$)$. There was no increase in the maximum grade of infection toxicity reported with PMitCEBO $(P=0.18)$ but these data must be treated with caution, as data on infection rates were incomplete. Hospitalisation rates and the number of days in hospital were comparable between $\mathrm{CHOP}$ and PMitCEBO $(P=0.3)$ (Table 8). Gastrointestinal toxicity was significantly increased in the CHOP arm $(P=0.008)$, especially nausea and vomiting $(P=0.013)$. Alopecia was also more common in the CHOP arm, $69 \%$ of patients developing alopecia in the CHOP arm compared with $57 \%$ in the PMitCEBO arm $(P=0.002)$. Grade 2-4 neuropathy was increased in the PMitCEBO arm $(P=0.035)$. Acute and chronic cardiac toxicity were comparable between both chemotherapy regimens. No formal testing of cardiac function was performed prior to commencing treatment. It is acknowledged that further chronic cardiac toxicity may become apparent during
Table 6 Maximum grade of haematological toxicity

\begin{tabular}{|c|c|c|c|c|c|}
\hline \multirow{2}{*}{\multicolumn{2}{|c|}{$\begin{array}{c}\text { CHOP } \\
(n=169) \\
\%\end{array}$}} & $\begin{array}{c}\text { PMitCEBO } \\
(n=172)\end{array}$ & $\begin{array}{c}\text { CHOP+GCSF } \\
(n=174)\end{array}$ & $\begin{array}{c}\text { PMitCEBO } \\
\text { +GCSF } \\
(n=I 70)\end{array}$ & \multirow{2}{*}{$\begin{array}{c}\text { Total } \\
(n=685) \\
\%\end{array}$} \\
\hline & & $\%$ & $\%$ & $\%$ & \\
\hline \multicolumn{6}{|c|}{ Haematological toxicity } \\
\hline 0 & 14 & I & | | & 5 & 8 \\
\hline | & 22 & 7 & 24 & 19 & 18 \\
\hline 2 & 21 & 21 & 24 & 21 & 22 \\
\hline 3 & 18 & 40 & 18 & 26 & 25 \\
\hline 4 & 24 & 31 & 24 & 28 & 27 \\
\hline \multicolumn{6}{|c|}{ Definitions of haematological toxicity } \\
\hline \multicolumn{6}{|c|}{ Grade $\operatorname{WBC}\left(\left.10^{9}\right|^{-1}\right) \quad P<\left(\left.10^{9}\right|^{-1}\right)$} \\
\hline 0 & $\geqslant 4.0$ & \multirow{2}{*}{\multicolumn{2}{|c|}{$\begin{array}{l}\text { Within normal limits } \\
\text { 75.0-normal }\end{array}$}} & \multicolumn{2}{|l|}{ Within normal limits } \\
\hline । & $3.0-3.9$ & 75 & & \multicolumn{2}{|l|}{ |0.0-normal } \\
\hline 2 & $2.0-2.9$ & & $50.0-74.9$ & $8.0-10.0$ & \\
\hline 3 & $1.0-1.9$ & & $25.0-49.9$ & \multirow{2}{*}{$\begin{array}{l}6.5-7.9 \\
<6.5\end{array}$} & \\
\hline 4 & $<1.0$ & & $<25.0$ & & \\
\hline
\end{tabular}

Table 7 Maximum grade of white blood cell toxicity

\begin{tabular}{|c|c|c|c|c|c|}
\hline & $\begin{array}{c}\text { CHOP } \\
(n=168)\end{array}$ & $\begin{array}{c}\text { PMitCEBO } \\
(n=172)\end{array}$ & $\begin{array}{c}\text { CHOP+GCSF } \\
(n=172)\end{array}$ & $\begin{array}{c}\text { PMitCEBO } \\
+ \text { GCSF }(n=169)\end{array}$ & $\begin{array}{c}\text { Total } \\
(n=68 I)\end{array}$ \\
\hline & $\%$ & $\%$ & $\%$ & $\%$ & $\%$ \\
\hline \multicolumn{6}{|c|}{ White blood cell toxicity } \\
\hline 0 & 32 & 6 & 33 & 30 & 25 \\
\hline I & 15 & 5 & 15 & 7 & $\mid 1$ \\
\hline 2 & 12 & 19 & 15 & 14 & 15 \\
\hline 3 & 18 & 40 & 15 & 22 & 24 \\
\hline 4 & 23 & 31 & 22 & 27 & 26 \\
\hline
\end{tabular}

Definitions of white blood cell toxicity

Grade $\operatorname{WBC}\left(10^{9} /\right)$

$0 \geqslant 4.0$

$1 \quad 3.0-3.9$

$2 \quad 2.0-2.9$

$3 \quad 1.0-1.9$

$4<1.0$

Table 8 In-patient days

\begin{tabular}{cccccc}
\hline & CHOP & PMitCEBO & $\begin{array}{c}\text { CHOP } \\
\text { +GCSF }\end{array}$ & $\begin{array}{c}\text { PMitCEBO } \\
\text { +GCSF }\end{array}$ & Total \\
\hline In-patient days & $\%$ & $\%$ & $\%$ & $\%$ & $\%$ \\
0 & 42 & 46 & 45 & 46 & 45 \\
$1-5$ & 12 & 16 & 18 & 21 & 17 \\
$6-10$ & 12 & 11 & 8 & 9 & 10 \\
$\mid 1-20$ & 10 & 7 & 9 & 8 & 9 \\
$21-30$ & 5 & 6 & 4 & 3 & 4 \\
$>30$ & 9 & 6 & 8 & 6 & 7 \\
Missing data & 11 & 8 & 7 & 8 & 8 \\
\hline
\end{tabular}

prolonged follow-up. There have been 36 cardiac deaths, 17 in the CHOP arm, and 19 in the PMitCEBO arm (Table 9)

The addition of G-CSF significantly reduced the incidence of grade 3 and 4 haematological toxicity $(P=0.024)$ due to a reduction in grade 3 and 4 leucopenia $(P=0.001)$ (Tables 6 and 7$)$. There was also a beneficial effect on the incidence of grade 3 and 4 anaemia associated with the use of G-CSF $(P=0.004)$. The addition of G-CSF did not appear to impact on the maximum grade of infection toxicity $(P=0.71)$, nor did it influence the hospitalisation rate or number of days in hospital $(P=0.41)$ (Table 8). Almost all time spent in hospital was related to sepsis. An exploratory 
Table 9 Causes of death

\begin{tabular}{|c|c|c|c|c|c|c|c|c|c|c|}
\hline \multirow[b]{2}{*}{ Cause of death } & \multicolumn{2}{|c|}{ CHOP } & \multicolumn{2}{|c|}{ PMitCEBO } & \multicolumn{2}{|c|}{ CHOP+GCSF } & \multicolumn{2}{|c|}{ PMitCEBO+GCSF } & \multicolumn{2}{|c|}{ Total } \\
\hline & N & $\%$ & N & $\%$ & N & $\%$ & N & $\%$ & N & $\%$ \\
\hline $\mathrm{NHL}$ & 87 & 77 & 84 & 80 & 71 & 71 & 76 & 76 & 318 & 76 \\
\hline \multicolumn{11}{|l|}{ Death on treatment } \\
\hline Infection & 4 & 4 & 5 & 5 & 2 & 2 & I & 1 & 12 & 3 \\
\hline Cardiac & 5 & 4 & 2 & 2 & 2 & 2 & 7 & 7 & 16 & 4 \\
\hline \multicolumn{11}{|l|}{ Death after treatment } \\
\hline Infection & 2 & 2 & 2 & 2 & 4 & 4 & 2 & 2 & 10 & 2 \\
\hline Cardiac & 3 & 3 & 7 & 7 & 7 & 7 & 3 & 3 & 20 & 5 \\
\hline Other & 1 & I & 2 & 2 & 3 & 3 & 5 & 5 & 11 & 3 \\
\hline Unknown & 3 & 3 & 0 & 0 & 4 & 4 & 0 & 0 & 7 & 2 \\
\hline Total $^{\mathrm{a}}$ & 113 & 100 & 105 & 100 & 99 & 100 & 100 & 100 & 417 & 100 \\
\hline
\end{tabular}

an total, 419 patients died. For two patients, who died from infection, it is not clear from the data whether they died on or after treatment (one in $\mathrm{CHOP}$ arm, one in $\mathrm{CHOP}+\mathrm{G}$ CSF arm).

analysis has also been performed restricted to patients who received $\mathrm{PMitCEBO}$, as this regimen was associated with more leucopenia. The proportion of patients treated with PMitCEBO without G-CSF who developed grade 3 or 4 leucopenia during treatment was $70 \%$ compared to $50 \%$ in those who received G-CSF (Table 7). There was no difference in infection toxicity or days in hospital $(P=0.95)$ between the two groups.

\section{DISCUSSION}

Special consideration of the management of elderly patients with aggressive NHL is necessary because of the increased risk of toxicity, morbidity and mortality from treatment and disease in this patient population. CHOP has been the most widely used regimen but treatment in the elderly is unsatisfactory, particularly when it is considered that many patients with co-morbidity, never receive such intensive combination chemotherapy regimens (Janssen-Heijnen et al, 2005). It is essential that regimens intended to reduce toxicity do not have a major negative impact on diseaseresponse and this requires large trials, which have rarely been carried out in the elderly population. For this reason, the target recruitment for this trial was 880 patients and although the trial had to be terminated early, $89 \%$ of recruitment had occurred. Furthermore, the estimation of numbers required was based on an anticipated FFS at 3 years of $30 \%$ with the CHOP only regimen. In fact, the 3 -year FFS in this arm was $44 \%$ and to see a $10 \%$ change from this baseline requires fewer patients, thus increasing the robustness of the results obtained.

The results of this trial are in accord with the poorer prognosis of older patients, but they also reaffirm that many elderly patients with histologically aggressive NHL can be cured of their disease. The 3-year overall survival for all patients of $46 \%$ compares favourably with other studies despite the high upper age-limit and the fact that over $50 \%$ of patients had poor prognostic disease as defined by the IPI (Osby et al, 2003; Pfreundschuh et al, 2004b; Feugier et al, 2005). Every effort should therefore be made to administer anthracycline-containing combination chemotherapy to elderly patients, if co-morbidity allows. Although outcome was worse in patients $\geqslant 70$ years, the overall survival at 3 years was over $35 \%$ justifying treatment with curative intent, although of course, increasing patient selection is inevitable with the older patients. The worst prognosis patient group, that is, $\geqslant 70$ years and IPI score $2-3$, still achieved a 3 year overall survival of $28 \%$.
This trial has demonstrated almost identical FFS and OS with CHOP and PMitCEBO. This equivalence of survival is despite the fact that the CR rate was less with PMitCEBO and presumably reflects that the earlier response assessment carried out with the shorter duration regimen underestimates the true response rate because of residual necrotic or fibrotic tissue (Surbone et al, 1988; Sweetenham et al, 1991). PMitCEBO is thus a valid alternative to CHOP contrasting with several other curtailed or modified regimens, which appear to be inferior (Meyer et al, 1995; Sonneveld et al, 1995; Bastion et al, 1997; Tirelli et al, 1998; Osby et al, 2003). A decision as to whether to use CHOP or PMitCEBO should therefore be based on the ease of administration and the comparative toxicities of the two regimens. PMitCEBO is given over a shorter treatment duration, although the number of hospital visits for injection of cytotoxic drugs is actually greater. PMitCEBO also induces less alopecia and less gastrointestinal disturbance. In addition, there is a reduced anthracycline dose with PMitCEBO. Assuming that $1 \mathrm{mg} \mathrm{m}^{-2}$ mitoxantrone equates to $5 \mathrm{mg} \mathrm{m}^{-2}$ doxorubicin (Posner et al, 1985), PMitCEBO contains about $30 \%$ less anthracycline than CHOP. This is potentially important in elderly patients in whom the incidence of cardiac toxicity may be higher than previously recognised and the threshold for damage may be within the range of the amount of doxorubicin given with CHOP (Swain et al, 2003).

The addition of prophylactic G-CSF to the two chemotherapy regimens, particularly $\mathrm{PMitCEBO}$, resulted in a reduction in episodes of severe leucopenia in accord with previous studies (Zinzani et al, 1997; Doorduijn et al, 2003; Osby et al, 2003). This did not however impact on the rate of admission to hospital or the duration of hospitalisation, which reflect the incidence and severity of neutropenic sepsis. This concurs with the study of 389 patients reported by Doordujin et al, who found no impact of GCSF on the incidence of infections or time in hospital in elderly patients receiving $\mathrm{CHOP}$, although the studies by Osby and Zinzani et al found less infections and fewer days in hospital associated with G-CSF use. Most importantly, the use of G-CSF in this study did not improve the response rates, FFS or OS concordant with the studies referred to above. Taken together, this supports the assertion that primary prophylaxis with G-CSF is not indicated in elderly patients with NHL treated with regimens such as CHOP, although G-CSF is clearly required if CHOP is 'time-escalated' with reduction of the interval between cycles to 2 weeks (Wunderlich et al, 2003). It may also be warranted in selected individuals at particularly high risk for developing neutropenic sepsis (Balducci et al, 2001). 
This trial was conducted before the advent of rituximab, and it is now widely accepted that rituximab should be given with chemotherapy in all cases of DLBC lymphoma (Pfreundschuh et al, 2004a; Feugier et al, 2005). This does not, however, detract from the finding in this study that PMitCEBO is an acceptable alternative to CHOP when the toxicity profile of PMitCEBO is preferable or more appropriate to the individual patient. The use of rituximab in addition to $\mathrm{CHOP}$ is associated with a marginal increase in neutropenia but not sufficient to affect the incidence of neutropenic fever or bacterial infections (Feugier et al, 2005). It is very unlikely, therefore, that the lack of clinical benefit found in

\section{REFERENCES}

Armitage J, Potter J (1984) Aggressive chemotherapy for diffuse histiocytic lymphoma in the elderly: increased complications with advancing age. J Am Geriatr Soc 32: 269-273

Balducci L, Lyman G, Ozer H (2001) Patients aged $\backslash\{\geqslant \mid\} 70$ are at high risk for neutropenic infection and should receive hemopoietic growth. J Clin Oncol 19: $1583-1585$

Bastion Y, Blay JY, Divine M, Brice P, Bordessoule D, Sebban C, Blanc M, Tilly H, Lederlin P, Deconinck E, Salles B, Dumontet C, Briere J, Coiffier B (1997) Elderly patients with aggressive non-Hodgkin's lymphoma: disease presentation, response to treatment, and survival - a Groupe d'Etude des Lymphomes de l'Adulte study on 453 patients older than 69 years. J Clin Oncol 15: 2945-2953

Bertini M, Freilone R, Vitolo U Botto B, Pizzuti M, Gavarotti P, Levis A, Orlandi E, Orsucci L, Pini M (1994) P-VEBEC: a new 8-weekly schedule with or without rG-CSF for elderly patients with aggressive nonHodgkin's lymphoma. Ann Oncol 5: 895-900

2001 Census (2001) Office of Population Censuses and Surveys. London, UK: Her Majesty's Stationery Office

Doorduijn JK, van der Holt B, van Imhoff GW, van der Hem KG, Kramer $\mathrm{MH}$, van Oers $\mathrm{MH}$, Ossenkoppele GJ, Schaafsma MR, Verdonck LF, Verhoef GE, Steijaert MM, Buijt I, Uyl-de Groot CA, van Agthoven M, Mulder AH, Sonneveld P (2003) CHOP compared with CHOP plus granulocyte colony-stimulating factor in elderly patients with aggressive non-Hodgkin's lymphoma. J Clin Oncol 21: 3041-3050

Feugier P, Van Hoof A, Sebban C, Solal-Celigny P, Bouabdallah R, Ferme C, Christian B, Lepage E, Tilly H, Morschhauser F, Gaulard P, Salles G, Bosly A, Gisselbrecht C, Reyes F, Coiffier B (2005) Long-term results of the R-CHOP study in the treatment of elderly patients with diffuse large B-cell lymphoma: a study by the Groupe d'Etude des Lymphomes de l'Adulte. J Clin Oncol 23: 4117-4126

Fisher RI, Gaynor ER, Dahlberg S, Oken MM, Grogan TM, Mize EM, Glick JH, Coltman Jr CA, Miller TP (1993) Comparison of a standard regimen (CHOP) with three intensive chemotherapy regimens for advanced non-Hodgkin's lymphoma. $N$ Engl J Med 328: 1002 - 1006

Gerhartz H, Engelhard M, Meusers P, Brittinger G (1993) Randomised double-blind, placebo-controlled, phase III study of recombinant human-granulocyte-macrophage-colony-stimulating factor as adjunct to induction treatment of high-grade malignant non-Hodgkin's lymphoma Blood 82: 2329-2339

Janssen-Heijnen M, van Spronsen D, Lemmens V, Houterman S, Verheija K, Coebergh J (2005) A population-based study of severity of comorbidity among patients with non-Hodgkin's lymphoma: prognostic impact independent of International Prognostic Index. Br J Haematol 129: $597-606$

Kaplan EL, Meier P (1958) Non parametric estimation from incomplete observations. J Am Statist Assoc 53: 457-481

Limat S, Demesmay K, Voillat L, Bernard Y, Deconinck E, Brion A, Sabbah A, Woronoff-Lemsi M, Cahn J (2003) Early cardiotoxicity of the CHOP regimen in aggressive non-Hodgkin's lymphoma. Ann Oncol 14: $277-281$

Linch D, Smith P, Hancock B, Hoskin P, Cunningham D, Newland A, Milligan D, Stevenson P, Wood J, MacLennan K, Vaughan B, Vaughan G, Gregory W (2000) A randomized BNLI trial of CHOP versus a weekly multi-agent regimen (PACEBOM) in patients with histologically aggressive non-Hodgkin's lymphoma. Ann Oncol 11: 87-90

Mainwaring P, Cunningham D, Gregory W, Hoskin P, Hancock B, Norton A, MacLennan K, Smith P, Hudson G, Linch D (2001) Mitoxantrone is this study with G-CSF use would be different with a rituximab containing regimen.

\section{ACKNOWLEDGEMENTS}

Dr Burton is supported by a grant from the Lymphoma Research Trust. The Clinical Trials Centre is supported by Cancer Research UK, Lymphoma Research Trust and Lymphoma Association. This study was carried out with ethical approval. superior to doxorubicin in a multiagent weekly regimen for patients older than 60 with high-grade lymphoma: results of a BNLI randomized trial of PAdriaCEBO versus PMitCEBO. Blood 97: 2991 - 2997

McNally R, Roman E, Cartwright R (1999) Leukaemias and Lymphomas: time trends in the UK. Cancer Causes Control 10: 35-42

Meyer R, Browman G, Samosh M, Benger A, Bryant-Lukosius D, Wilson W, Frank G, Leber B, Sternbach M, Foster G (1995) Randomized phase II comparison of standard CHOP with weekly CHOP in elderly patients with non-Hodgkin's lymphoma. J Clin Oncol 13: 2386-2393

Muller A, Ihorst G, Mertelsmann R, Engelhardt M (2005) Epidemiology of non-Hodgkin's lymphoma (NHL): trends, geographic distribution and etiology. Ann Haematol 84: 1-12

Niitsu N, Umeda M (1995) COP-BLAM regimen combined with G-CSF in high grade non-Hodgkin's lymphoma. Eur J Haematol 55: 88-92

Osby E, Hagberg H, Kvaloy S, Teerenhovi L, Anderson H, Cavallin-Stahl E, Holte H, Myhre J, Pertovaara H, Bjorkholm M, Nordic Lymphoma Group (2003) CHOP is superior to CNOP in elderly patients with aggressive lymphoma while outcome is unaffected by filgrastim treatment: results of a Nordic Lymphoma Group randomized trial. Blood 101: $3840-3848$

Pettengell R, Gurney H, Radford J (1992) Granulocyte colony stimulating factor to prevent dose-limiting neutropenia in non-Hodgkin's lymphoma: a randomised controlled trial. Blood 80: $1430-1436$

Pfreundschuh M, Trumper L, Gill D, Osterborg A, Pettengell R, Trneny M, Imrie K, Walewski J, Zinzani P-L, Loeffler M (2004a) First analysis of the completed MabThera international (MInT) trial in young patients with low-risk diffuse large B-cell lymphoma (DLBCL): Addition of rituximab to a CHOP-like regimen significantly improves outcome of all patients with the identification of a very favourable subgroup with IPI $=0$ and no bulky disease. Blood 104, abstract 157

Pfreundschuh M, Trumper L, Kloess M, Schmits R, Feller A, Rube C, Rudolph C, Reiser M, Hossfeld D, Eimermacher H, Hasenclever D, Schmitz N, Loeffler M (2004b) Two-weekly or 3-weekly CHOP chemotherapy with or without etoposide for the treatment of elderly patients with aggressive lymphomas: results of the NHL-B2 trial of the DSHNHL. Blood 104: 634-641

Posner LE, Dukart G, Goldberg J, Bernstein T, Cartwright K (1985) Mitoxantrone: an overview of safety and toxicity. Invest New Drugs 3: 123-132

Silvestri F, Velisig M, Fanin R, Virgolini L, Zaja F, Barillari G, Baccarani M (1995) G-CSF allows the delivery of effective doses of CHOP and CVP regimens in non-Hodgkin lymphomas. Leuk Lymphoma 16: 465-470

Sonneveld P, de Ridder M, van der Lelie H, Nieuwenhuis K, Schouten $\mathrm{H}$, Mulder A, van Reijswoud I, Hop W, Lowenberg B (1995) Comparison of doxorubicin and mitoxantrone in the treatment of elderly patients with advanced diffuse non-Hodgkin's lymphoma using CHOP versus CNOP chemotherapy. J Clin Oncol 13: 2530-2539

Surbone A, Longo DL, DeVita Jr VT, Ihde DC, Duffey PL, Jaffe ES, Solomon D, Hubbard SM, Young RC (1988) Residual abdominal masses in aggressive non-Hodgkin's lymphoma after combination chemotherapy: significance and management. J Clin Oncol 6: 1832-1837

Swain S, Whaley F, Ewer M (2003) Congestive heart failure in patients treated with doxorubicin. Cancer 97: 2869-2879

Sweetenham J, Mead G, Whitehouse J (1991) Intensive weekly combination chemotherapy for patients with intermediate-grade and high-grade nonHodgkin's lymphoma. J Clin Oncol 9: 2202-2209

The International Non-Hodgkin's Lymphoma Prognostic Factors Project (1993) A predictive model for aggressive non-Hodgkin's lymphoma. $N$ Engl J Med 329: 987-994 
The Non-Hodgkin's Lymphoma Classification Project (1997) Effect of age on the characteristics and clinical behaviour of non-Hodgkin's lymphoma patients. Ann Oncol 8: 973-978

Tirelli U, Errante D, Van Glabbeke M, Teodorovic I, Kluin-Nelemans JC, Thomas J, Bron D, Rosti G, Somers R, Zagonel V, Noordijk EM (1998) CHOP is the standard regimen in patients $>$ or $=70$ years of age with intermediate-grade and high-grade non-Hodgkin's lymphoma: results of a randomized study of the European Organization for Research and Treatment of Cancer Lymphoma Cooperative Study Group. J Clin Oncol 16: $27-34$

Wunderlich A, Kloess M, Reiser M, Rudolph C, Truemper L, Bittner S, Schmalenberg H, Schmits R, Pfreundschuh M, Loeffler M, German HighGrade Non-Hodgkin's Lymphoma Study Group (DSHNHL) (2003) Practicability and acute haematological toxicity of 2- and 3-weekly
CHOP and CHOEP chemotherapy for aggressive non-Hodgkin's lymphoma: results from the NHL-B trial of the German High-Grade Non-Hodgkin's Lymphoma Study Group (DSHNHL). Ann Oncol 14: $881-893$

Zagonel V, Babare R, Merola MC, Talamini R, Lazzarini R, Tirelli U, Carbone A, Monfardini S (1994) Cost-benefit of G-CSF administration in older patients with non-Hodgkin's lymphoma treated with combination chemotherapy. Ann Oncol 5: S127-S132

Zinzani PL, Pavone E, Storti S, Moretti L, Fattori PP, Guardigni L, Falini B, Gobbi M, Gentilini P, Lauta VM, Bendandi M, Gherlinzoni F, Magagnoli M, Venturi S, Aitini E, Tabanelli M, Leone G, Liso V, Tura S (1997) Randomized trial with or without granulocyte colony-stimulating factor as adjunct to induction VNCOP-B treatment of elderly high-grade nonHodgkin's lymphoma. Blood 89: 3974-3979 